\title{
Amberlit XAD-4 Polimerinin Biyosorbent Katkı Malzemesi Badem Kabuğu Kullanılarak Sulu Çözeltiden Cd Giderilmesi
}

\author{
*1'Ibrahim Teğin ve ${ }^{1}$ Selma Akdeniz \\ ${ }^{*}$ Siirt Üniversitesi, Fen Edebiyat Fakültesi, Kimya Bölümü, Türkiye \\ ibrahim.tegin@gmail.com, akdeniz73562@hotmail.com \\ Geliş Tarihi: 2017-02-01 Kabul Tarihi: 2017-06-30
}

\section{Öz}

Bu çalışmada, biyosorbent olarak badem kabuğu ile immobilize edilmiş amberlit XAD-4 polimerinin üzerine Cd(II) iyonlarının katı faz özütleme yöntemi ile zenginleştirilme şartları araştırıldı. Bunun yanında, geri kazanım verimi üzerine ortamın pH etkisi, elüent türü ve derişimi, çözelti akış hızı, çözelti hacminin etkisi, tuz etkisi, kolonun tekrarlanabilirliği, çevre örneklerine ve sertifikalı referans maddeye uygulanması araştırılmıştır. Önerilen yöntem ile $\mathrm{Cd}$ için 10 kat zenginleşme sağlanmıştır. Optimum şartlarda, \% 95 güven seviyesinde $\mathrm{Cd}$ geri kazanım verimi \% 98,87 $\pm 3,85$ olarak bulunmuştur. Ayrıca \% 95 güven seviyesinde, 3 tekrar deneyi için \% bağıl standart sapma değeri $\mathrm{Cd}$ için \% 3,21 olarak bulunmuştur.

Anahtar kelimeler: Amberlit XAD-4, solid faz ekstraksiyonu, eser element, $\mathrm{Cd}$

\section{The Removal of Cd From Aqueous Solution Using Sorbents Almont Shell Immobilized On Amberlite XAD-4}

\author{
*1 İbrahim Teğin and ${ }^{1}$ Selma Akdeniz \\ ${ }^{*}$ Siirt University, Faculty of Science and Art, Department of Chemistry, Turkey \\ Received date: 2017-02-01 Accepted date: 2017-06-30
}

\begin{abstract}
In this study; statistical process control is being used on spinwelding machine process. All parameters that used on process control is tested with various type of experiments and effect of these parameters to the capability is analysed. Mini-tap part-cabality analyses, pull-of tests of samples, leaking test, shock test, burst test, visual and optic microscope controls of crosscut samples are examined. As a result of all detailed analyses; special appropriate parameters for machine are defined and with statistical process control - errorproof works(Poka-Yoke, sensor) process is kept under control and ensure its continuity. With this conclusion scrap parts ratio is kept in minimum level in this spinwelding machine.
\end{abstract}

Keywords: Amberlite XAD-4, solid phase extraction, trace element, $\mathrm{Cd}$

\section{Giriş}

Gelişen dünyada ağır metal kirliliği, halk sağlı̆̆ı ve doğal hayat için önemli bir risk olup her geçen gün kapsamı genişleyip, etkileri artmaktadır. $\mathrm{Bu}$ elementlerin çok düşük miktarlarda bulunması çevre ve insan sağlığı için önemliyken, fazla miktarlarının akut ve kronik zehirlenmeye neden olduğu bilinmektedir [1].

Eser element analizinde kullanılan kat1-sıv1 ekstraksiyon tekniği, ucuz, kolay ve hızlı olmasından dolayı çok yaygın ve sıkça kullanılan bir tekniktir
[2]-[5]. Aynı zamanda, bu teknikle yapılan analizler, büyük numune hacimleri ile çalışabilme ve en önemlisi yüksek bir zenginleştirme faktörü elde etme gibi önemli avantajlar sağlamaktadır $\mathrm{Bu}$ yöntemde analit doğrudan doğruya model çözelti ortamına eklenir, daha sonra hazırlanan kolona yerleştirilir ve uygun kolon dolgu maddesiyle doldurulmuş kolondan geçirilir. Proba bağlanan iyon, uygun bir eluent çözeltisi ile elüe edildikten sonra, elüasyon çözeltisinin içeriği, atomik absorpsiyon spektroskopisi gibi bir enstrümental cihazla analizi yapılır [6]-[8]. Son yıllarda, çözeltiden ağır metali uzaklaştırmak için düşük maliyetli biyosorbent 
geliştirme çabaları hızlanmıştır. Biyosorpsiyon işlemi, bir katı faz (sorbent veya adsorban) ve metal iyonlarını adsorbe etmek için çözünmüş türleri barındıran bir sıvı faz içerir. Biyosorpsiyon, ağır metallerin biyokütle ile hızlı ve geri dönüşümlü bir reaksiyonudur. Biyomateryalden elde edilen yan ürünler ucuz bir biyosorbent kaynağıdır. Turbo, linyit ve hümik asitler, işlenmiş aktif karbonlar ve kömür temelli doğal adsorbanlar, kitosan esaslı polimerik sürfaktanlar, uçucu kül, mikrobik biyokütle ve soya fasulyesi tekneleri, ceviz kabukları, pamuk tohumu gövdeleri ve misır koçanları, ceviz kabuğu, hindistan cevizi elyafi, mantar biyokütlesi, yağsız pirinç kepeği, pirinç gövdeleri, soya gövdeleri ve pamuk tohumu gövdeleri, buğday kepeği, pamuk ve hardal tohumu kekleri, kabuklu hayvanlar diğer tarımsal ürünler gibi biyosorbanları kullanarak ağır metallerin etkin bir şekilde uzaklaştırılması için çeşitli fikirler araştırılmış ve geliştirilmiştir [9]. Biyosorbent olarak badem kabuğunu kullanarak $\mathrm{Cr}$ (VI) [9], Pb (II) [10], $\mathrm{Ni}(\mathrm{II}), \mathrm{Cd}(\mathrm{II})$ [11], Zn (II) ve Cu(II) [12], [13] iyonlarının çözeltiden uzaklştırılmasına çalışılmıştır. Bunun yanında badem kabuğunu kullanarak asit boyalarının çözeltiden uzaklaştılmasına çalışılmiştır [14].Yapılan çalışmalarda badem kabuğu kullanarak adsorpsiyon kapasitesi $\mathrm{Pb}(\mathrm{II})$ için 8,08 mg g-1[10], $\mathrm{Cr}$ (VI) için 3,40 mg g-1[9] bulunmuştur.

Amberlite XAD adsorbentleri, oldukça çapraz bağlanmış, macroretülan polistiren, alifatik veya fenol-formaldehit kondensat polimerlere dayanan çok gözenekli küresel polimerlerdir. XAD reçineleri polimerik matrise dayanarak iki ana gruba ayrılır. Polistiren-divinil benzen esaslı XAD-1, XAD-2, XAD-4, XAD-16, XAD-1180, XAD-2000, XAD2010 ve poliakrilik asit ester esaslı XAD-7, XAD-8 ve $\mathrm{XAD}-11$ reçineleridir [15]. XAD reçineleri, şelatlayıcı ligandların immobilizasyonu için kopolimer omurgası olarak gözeneklilik, üniform gözenek boyutu dağılımı, yüksek yüzey alanı, dayanıklılık ve asit, baz ve oksitleyici ajanlara karşı kimyasal kararlılık gibi üstün özelliklere sahiptir. Literatürde, sulu çözeltiden metal iyon ayrımı ve ön konsantrasyon için uygun olan XAD-2 [16], XAD-4 [6], [17]-[19] ve XAD-7 [20] kopolimerlerinden sentezlenen birçok kenetleme iyon değiştiricisi tarif edilmiştir [7]. Absorplayıcı reçine (polisitiren divinil benzen) olarak Amberlite XAD-4, yüzey alan1 750 $\mathrm{m}^{2} \mathrm{~g}^{-1}$, gözenek çap1 $4 \mathrm{~nm}$ ve gözenek boyutu 20-60 mesh olup Sigma firması tarafinfan ürtilmektedir [6]. Pyrocatechol [15], 2-hidroksi-3metoksibenzaldehit [16], o-aminobenzoik asit [7] Salinivibrio Sharmensis [6] ve Pleurotus eryngii [21] ile işlevselleştirilen XAD reçineleri kullanılarak Ni, $\mathrm{Co}, \mathrm{Cu}, \mathrm{Cd}$ ve $\mathrm{Co}$ gibi tayin edilen ve zenginleştirme yapılan eser elementlerden bir kaç çalışma örnek veriliebilir [21].

Ağır metallerin analizinde yaygın olarak alevli atomik absorpsiyon spektroskopisi [19], [22]-[26], elektrotermal atomik absorpsiyon spektroskopisi [27]-[29], indüktif eşleşmiş plazma-optik emisyon spektroskopisi[30]-[33] ve indüktif eşleşmiş plazma-kütle spektroskopisi [34]-[36][21] gibi analitik teknikler kullanılmaktadır.

$\mathrm{Bu}$ çalışmanın amacı, biyosorbent ile modifiye edilmiş Amberlit XAD-4'ü [1], [7], [24], [29], [32], [37]-[39].katı faz özütleme yönteminde adsorban olarak kullanarak eser düzeydeki Cd(II) iyonunun zenginleştirme şartlarını araştırmaktır. Çalışılan metal iyonların geri kazanma verimine ortamın $\mathrm{pH}$ '1, elüent türü ve derişimi, çözelti akış hızı, çözelti hacminin etkisi, tuz etkisi, kolonun tekrarlanabilirliği, sertifikalı referans madde (Aquatic Plant Sample) ve çevre örneklerine uygulanması incelenmiştir.

\section{Malzeme ve Yöntem}

\subsection{Kullanılan Aletler ve Çalışma Koşulları}

Bedem kabuğu immobilize edilmiş Amberlit XAD4 örneğinin Xışını spektromu için X - Işınları Toz Difraksiyon (XRD) Bruker AXS D8 Advance Model cihaz ile yapılmıştır. SEM görünümü için Taramalı Elektron Mikroskobu (SEM) LEO 440 Computer Controlled Digital model kullanılmıştır. TG/DTA analizi için Termogravimetrik ve Diferansiyel Termal Analiz (TG/DTA) Perkin Elmer Diamond model cihaz ile yapılmıştır. FT-IR analizleri için Perkin Elmer Spectrum 100 FT-IR model alet kullanılmıştır. Yüzey Alanı ve Porozite analizi için de Yüzey Alanı ve Porozite (Gözeneklilik) Analiz (BET) Micromeritics Gemini VII Surface Area and Porosity model cihaz ile yapılmıştır. pH ölçümleri için HANNA Instruments HI $2211 \mathrm{Ph} /$ ORP Meter markalı $\mathrm{pH}$ metre ve çözeltiyi kolon üzerinden geçirmek için Watson Marlow 120 S markalı peristaltik pompa kullanılmıştır. Karıştırma işlemleri için IKA Werke RT-10P markalı manyetik karıştırıcıdan yararlanılmıştır. Çalışma suresince çapı $1 \mathrm{~cm}$ ve boyu $10 \mathrm{~cm}(1.0 \mathrm{~cm}$ x $10 \mathrm{~cm})$ katı faz ekstraksiyon filtrasyon kolonları ve metal iyonlarının konsantrasyonunu belirlemek için Perkin Elmer AAnalyst 700 markalı Atomik Absorpsiyon Spektrometresi kullanılmıştır. Atomik absorpsiyon spektrofotometrenin çalışma koşulları ve çalışmada yer alan analitin analitiksel karakteristikleri Tablo 1 ve Tablo 2'de verilmiştir. 
Tablo 1. Atomik absorbsiyon spektrofotometresinin çalışma koşulları

\begin{tabular}{ll}
\hline & $\mathrm{Cd}^{2+}$ \\
\hline Dalga Boyu (nm) & $228,8-326,1$ \\
Asetilen Akış Hızı (L/dakika) & 1,8 \\
Bağıl Gürültü & $0,9-1,0$ \\
Konsantrasyon (mg/L) & $0,028-11$ \\
\hline
\end{tabular}

Tablo 2. Çalışmada yer alan analitin analitiksel karakteristikleri

\begin{tabular}{clllllc}
\hline Metot & Element & Lineer Aralık (C) & Eğim & Kesim & $\mathrm{R}^{2}$ & Regresyon Eşitliği \\
\hline AAS & $\mathrm{Cd}^{2+}$ & $0,028-11$ & 0,09157 & 0,001137 & 0,9975 & $\mathrm{~A}=0,1841+0,0023$ \\
\hline $\mathrm{A}=\mathrm{A}$
\end{tabular}

$\mathrm{A}=$ Absorbans, $\mathrm{C}=$ Konsantrasyon

Çalışma süresince kadmiyum çözeltileri günlük olarak, stok standart çözeltilerinden (Merck, 1000 $\mathrm{mg} / \mathrm{L})$ seyreltilerek hazırland1. BCR-670 Aquatic Plant Sample sertifikalı standart referans madde (SRM) örneği, Berghof Speed Wave (MWS-3) mikrodalga örnek çözücü sistemi kullanılarak çözünürleştirilmiştir. Çözünürleştirme için yaklaşık 0,50 g BCR-670 sertifikalı standart referans örneği tartılıp bir PTFE kabına konulmuş ve üzerine $10 \mathrm{~mL}$ $\mathrm{HNO}_{3}\left(\%\right.$ 65) ve $2 \mathrm{~mL} \mathrm{H} \mathrm{H}_{2}$ (\% 30) ilave edilip kapağı yaklaşık 25 dakika sonra kapatılmıştır. Aquatic Plant Sample sertifikalı standart referans maddesinin çözünürleştirilmesi için mikro dalga firın 1sıtma programı, Tablo 3'te verildiği gibi yapılmıştır. Daha sonra, kalıntı deiyonize su içerisinde çözündürülüp ve filtrelenmiştir. Süzülen çözelti, deiyonize su ile 50 mL'ye tamamlanmıştır.

Çalışmalarda kullanılan cam malzemeler sırasıyla deterjan, çeşme suyu, $1: 1 \mathrm{HNO}_{3}$, çeşme suyu, 1:1 $\mathrm{HCl}$, çeşme suyu ve son olarak deiyonize su ile iyice yıkanmıştır [40], [41]. Durulanan malzemeler etüvde $110{ }^{\circ} \mathrm{C}$ 'de kurutulup tekrar kullanıma hazır hale getirilmiştir.

Tablo 3. BCR-670 Aquatic plant sertifikalı refrans madde için mikro dalga firının çalışma programı

\begin{tabular}{lll}
\hline Step & 1 & 2 \\
\hline $\mathrm{T}\left({ }^{\circ} \mathrm{C}\right)$ & 150 & 190 \\
$\mathrm{P}(\mathrm{bar})$ & 50 & 50 \\
Power $(\%)$ & 70 & 90 \\
Ta $(\mathrm{dk}$ & 5 & 1 \\
Time $(\mathrm{dk})$ & 10 & 10 \\
\hline
\end{tabular}

\subsection{Adsorbentin Hazırlanması}

Amberlit XAD-4 kopolimerleri, farklı monomerler kullanılarak elde edilen geniş yüzey alanına sahip bir polimer çeşididir. Bu polimerler, sert ve değişmeyen gözeneklere sahiptir. Organik çözücülere, asit ve bazik ortamlara karşı dayanıklıdır. Deneyde kullanılan Amberlit XAD-4 polimerinin ortalama yüzey alanı $780 \mathrm{~m}^{2} / \mathrm{g}$ ve gözenek çap1 $5 \mathrm{~nm}$, polistiren-divinilbenzen kopolimeri olup apolar özelliğine sahiptir. $\mathrm{Bu}$ polimer Sigma Aldrich firmasından temin edilmiştir. Kolonlarda kullanmak üzere yaklaşık $50 \mathrm{~g}$ Amberlit XAD-4 alınarak sırasıyla etanol, $4 \mathrm{M} \mathrm{HCl}$ ve saf su içinde 60 dakika süreyle temasta tutulmuştur. Daha sonra yıkanıp 105 ${ }^{0} \mathrm{C}$ 'da kuruyana kadar etüvde bekletilmiş ve kurutulan Amberlit XAD-4 polimeri daha sonraki çalışmalarda kullanılmak üzere polietilen şişelerde muhafaza edilmiştir [6], [21].

\subsection{Biyosorbentin Hazırlanmast}

Biyosorbent olarak kullanılan Badem kabuğu memert markalı ögütücüde öğütülüp daha sonra -60 mesh boyutundaki elekten geçirilmiştir. Biyosorbente bulunan safsızlıkları uzaklaştırmak için [42] biyosorbent destile su ile yıkanıp tekrar etüvde kurutulmuştur. Daha sonra havanda öğütülüp -60 mesh elekten geçirilmiştir.

\subsection{SPE Kolonunun Hazırlanmast}

Hazırlanan biyosorbentten 0,250 g, 1,00 g Amberlit XAD-4 ve $10 \mathrm{~mL}$ saf su 60 dakika boyunca manyetik karıştırıcıyla karıştırılmıştır. Elde edilen karışım etüvde kurutulduktan sonra karışım tekrar -60 mesh boyutundaki elekten geçirilmiştir. Hazırlanan karışım çapı $1 \mathrm{~cm}$ ve boyu $10 \mathrm{~cm}$ olan katı faz ekstraksiyon (SPE) kolonlarına doldurulmuş ve. deneyde kullanmak üzere hazır hale getirilmiştir. [21], [43]. 


\subsection{Kolon Dolgu Materyalinin Karakterizasyonu}

Biyosorbent olarak kullanılan badem kabuğu, sorbent olarak Amberlit XAD-4 ve badem kabuğu ile immobilize edilmiş Amberlit XAD-4'ün FT IR analizi yapılmış ve elde edilen sonuçlar Şekil 1'de verilmiştir.

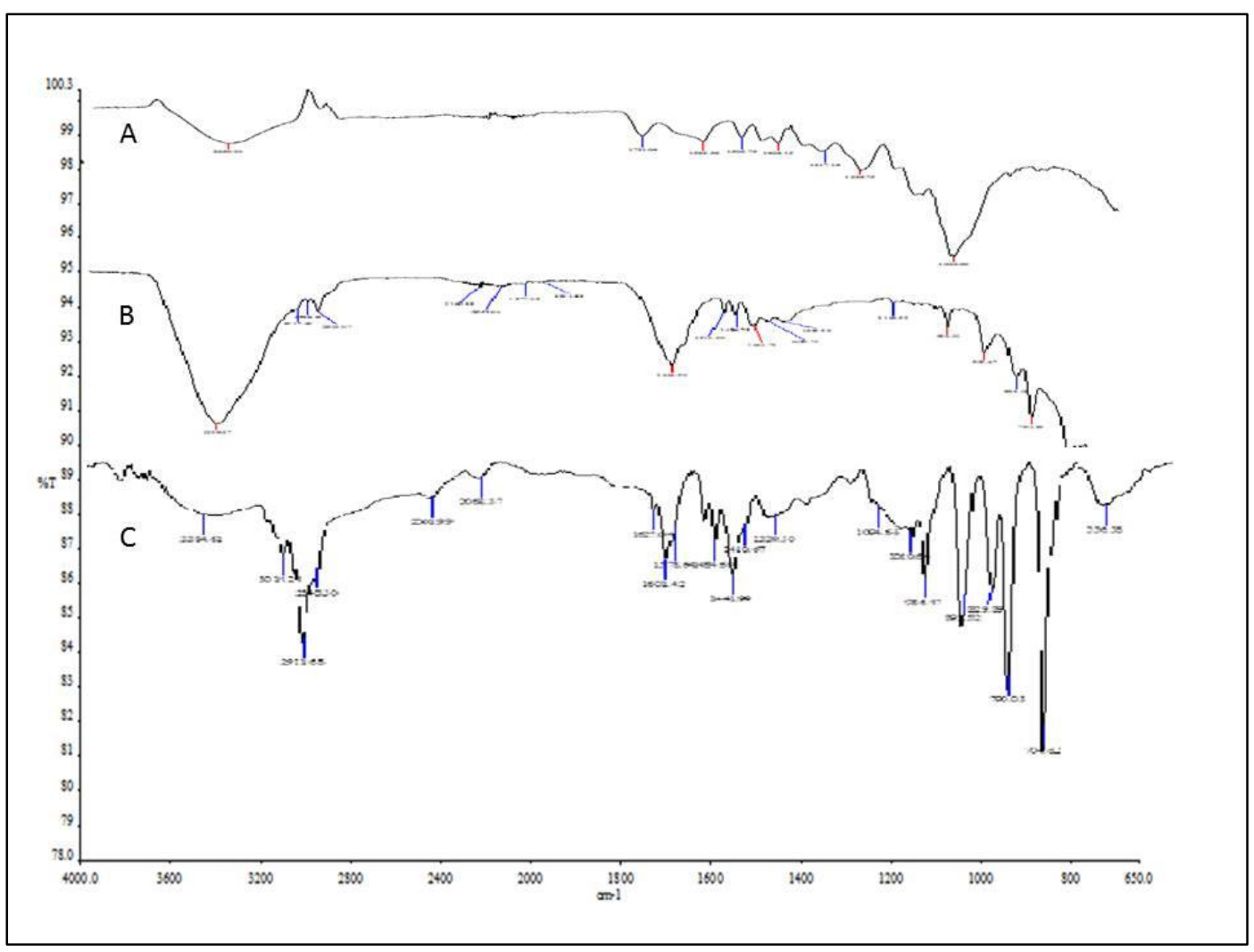

Şekil 1. A: Badem kabuğu, B: Amberlit XAD-4 , C: badem kabuğu ile immobilize edilmiş Amberlit XAD-4'ün FT-IR grafiği

Şekil 1'deki spektrumlar incelendiğinde kolon dolgu maddesinin karmaşık yapısını gösteren bir dizi adsorpsiyon pikleri görülmektedir. Analiz edilen tüm spektrumlar, $3300-3500 \mathrm{~cm}^{-1}$ de, alkolik, fenolik veya asidik $\mathrm{OH}^{\prime}$ 'n hidrojen bağıyla varlığını gösteren bantlara sahiptir. $3394-3384 \mathrm{~cm}^{-1}$ arasındaki yayvan pik, makromoleküler birleşmenin bağlı hidroksil gruplarının (selüloz, pektin, vb.) olduğunu gösterir. 2923 ve $2911 \mathrm{~cm}^{-1}$ 'de gözlemlenen tepe noktaları C$\mathrm{H}$ grubuna ait olabilir. 2301-2068 cm-1 C-N grubuna bağlı üçlü bağ piki olabilir.1603-1601 $\mathrm{cm}^{-1}$ çevresindeki bantlar, serbest ve esterlenmiş karboksil gruplarının varlığını gösterir. IR spektrumları, 1484 ve $1430 \mathrm{~cm}^{-1}$ aralı̆̆ında bantlar karbonların farklı yüzey yapıları olan alifatik, aromatik, halkalı olduğunu göstermektedir. 1023 ve $981 \mathrm{~cm}^{-1}$ 'deki bant, alkollerin ve karboksilik asitlerin C-O olduğu gösterir [10], [12], [44].

Badem kabuğu, Amberlit XAD-4 polimeri ve badem kabuğu ile immobilize edilmiş Amberlit XAD-4'ün taramalı elektronik mikroskobu (SEM) analizi yapılmış ve elde edilen sonuçlar Şekil 2-4'te verilmiştir. Bunun yanında badem kabuğu ile immobilize edilmiş Amberlit XAD-4'ün X-1şını difraksiyon (XRD) analizi Şekil 5'te, Termogravimetrik analiz (TG/DTA) grafiği Şekil 6'da ve BET analizi Tablo 4'te verilmiştir. 


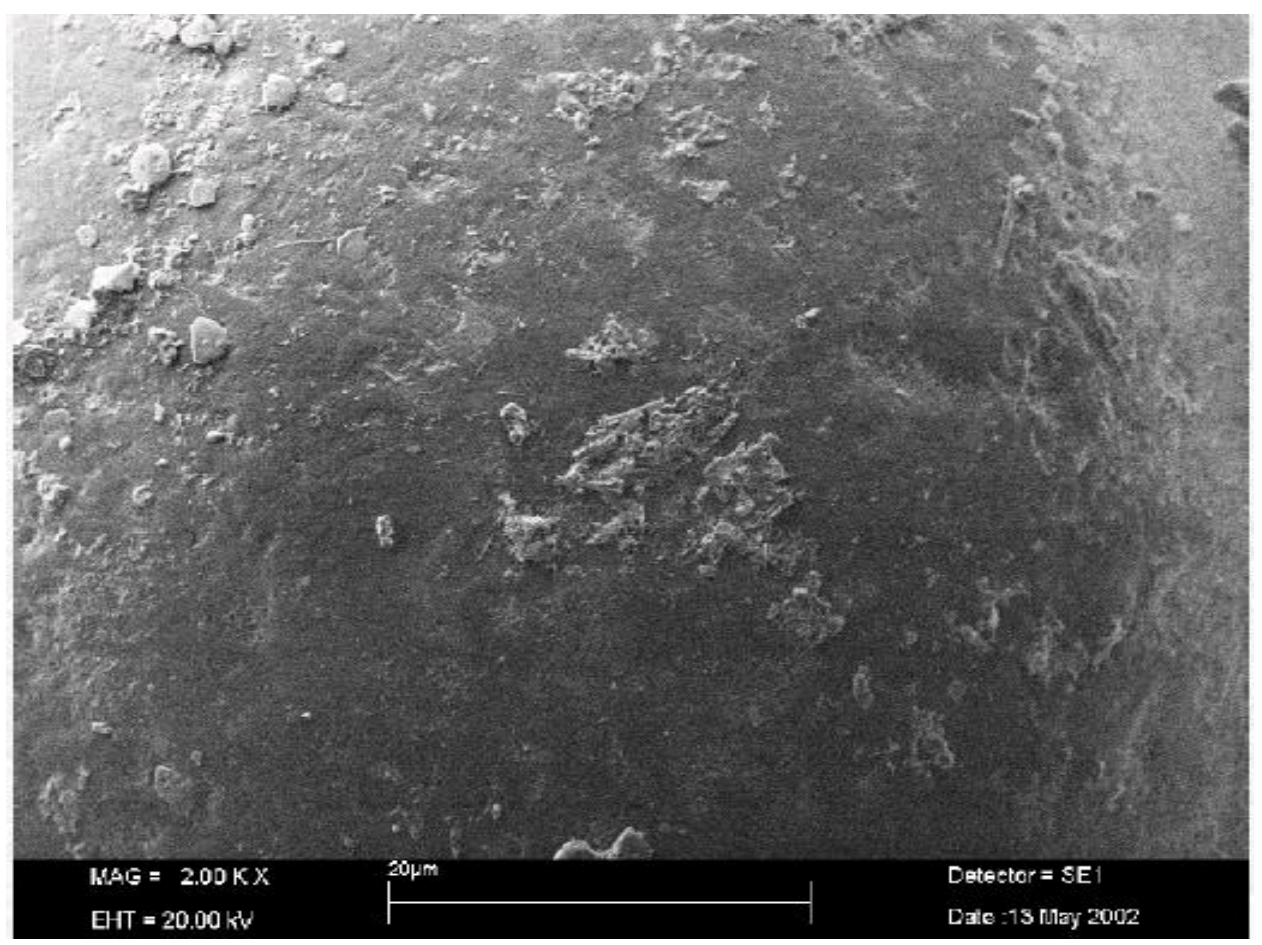

Şekil 2 Amberlit XAD-4'ün taramalı elektronik mikroskobu (SEM) Görünümü [45]

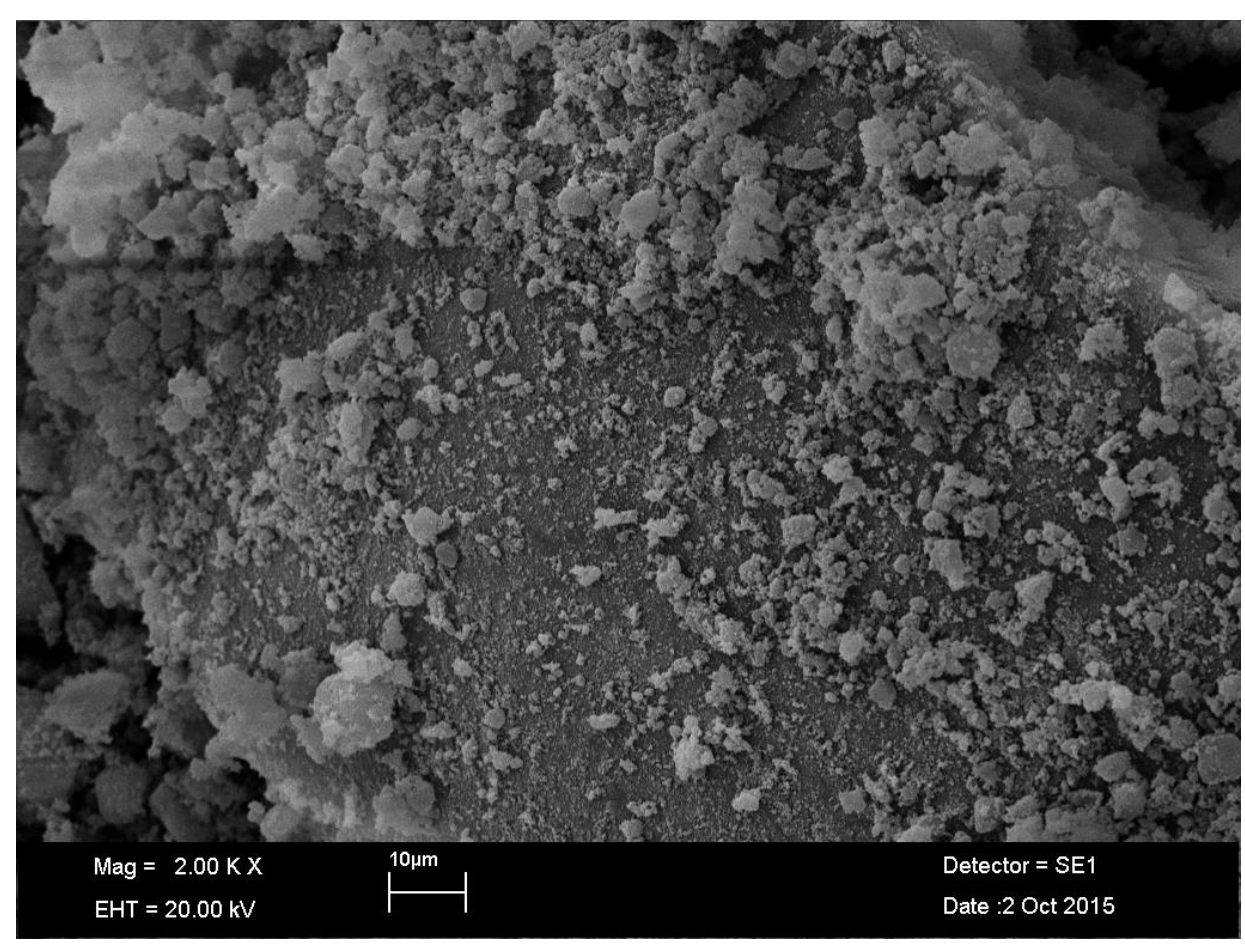

Şekil 3. Badem kabuğu ile immobilize edilmiş Amberlit XAD-4'ün taramalı elektronik mikroskobu (SEM) görüümü 


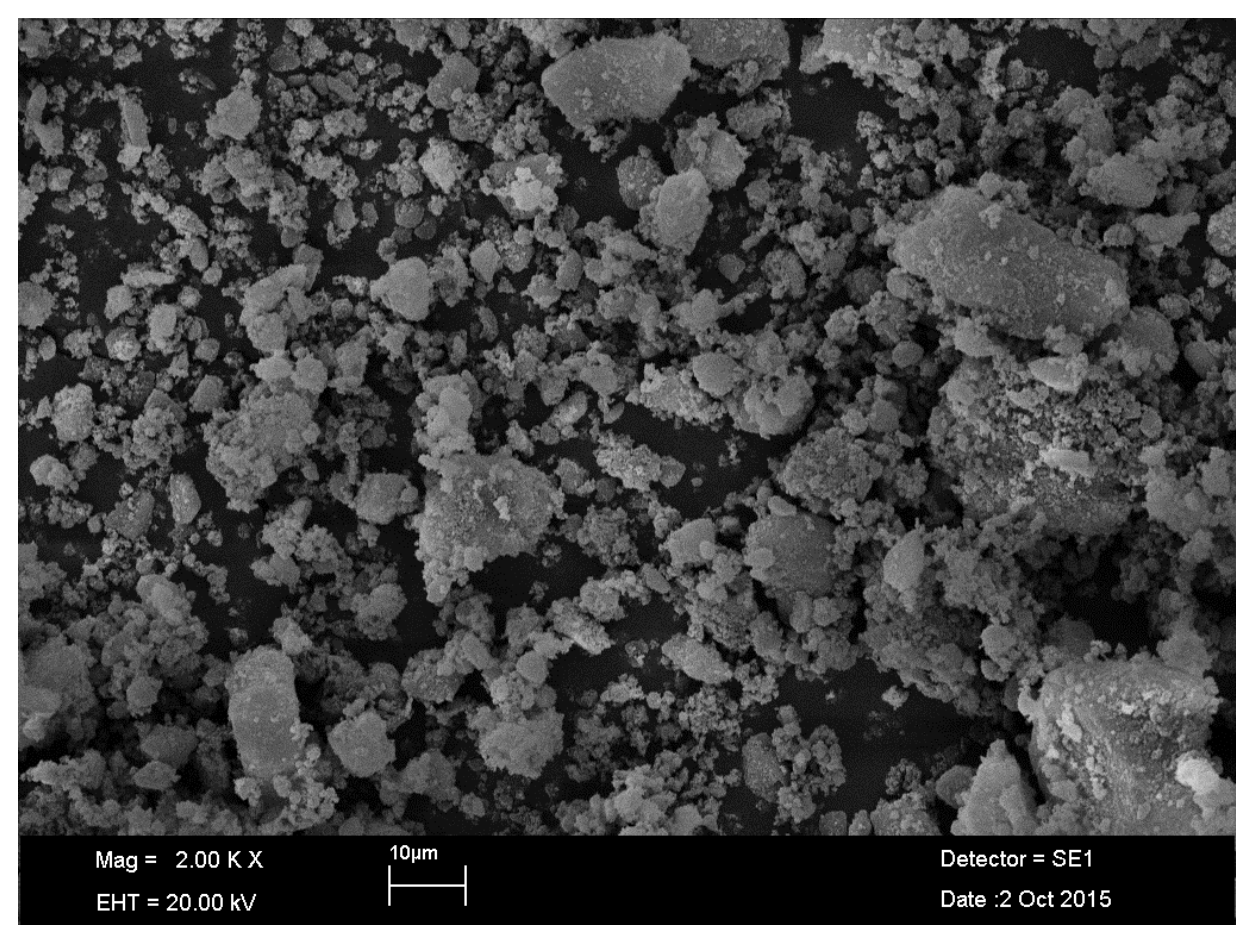

Şekil 4. Badem kabuğu ile immobilize edilmiş amberlit XAD-4 kolonundan Cd(II) geçirilmiş halinin taramalı elektronik mikroskobu (SEM) görüümü

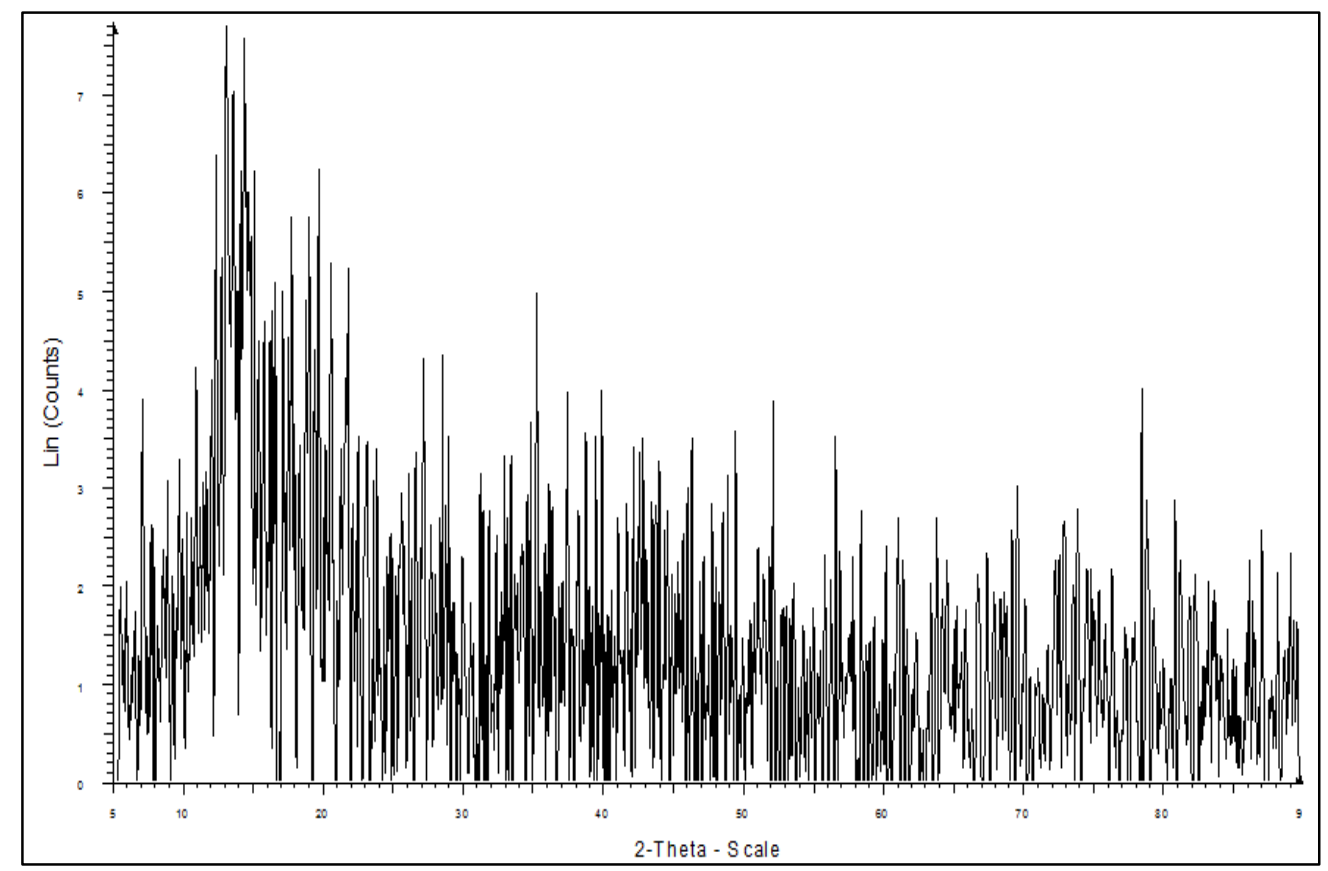

Şekil 5. Badem kabuğu ile immobilize edilmiş Amberlit XAD-4 kolon dolgu maddesinin X-1şını difraksiyon (XRD) görünümü 


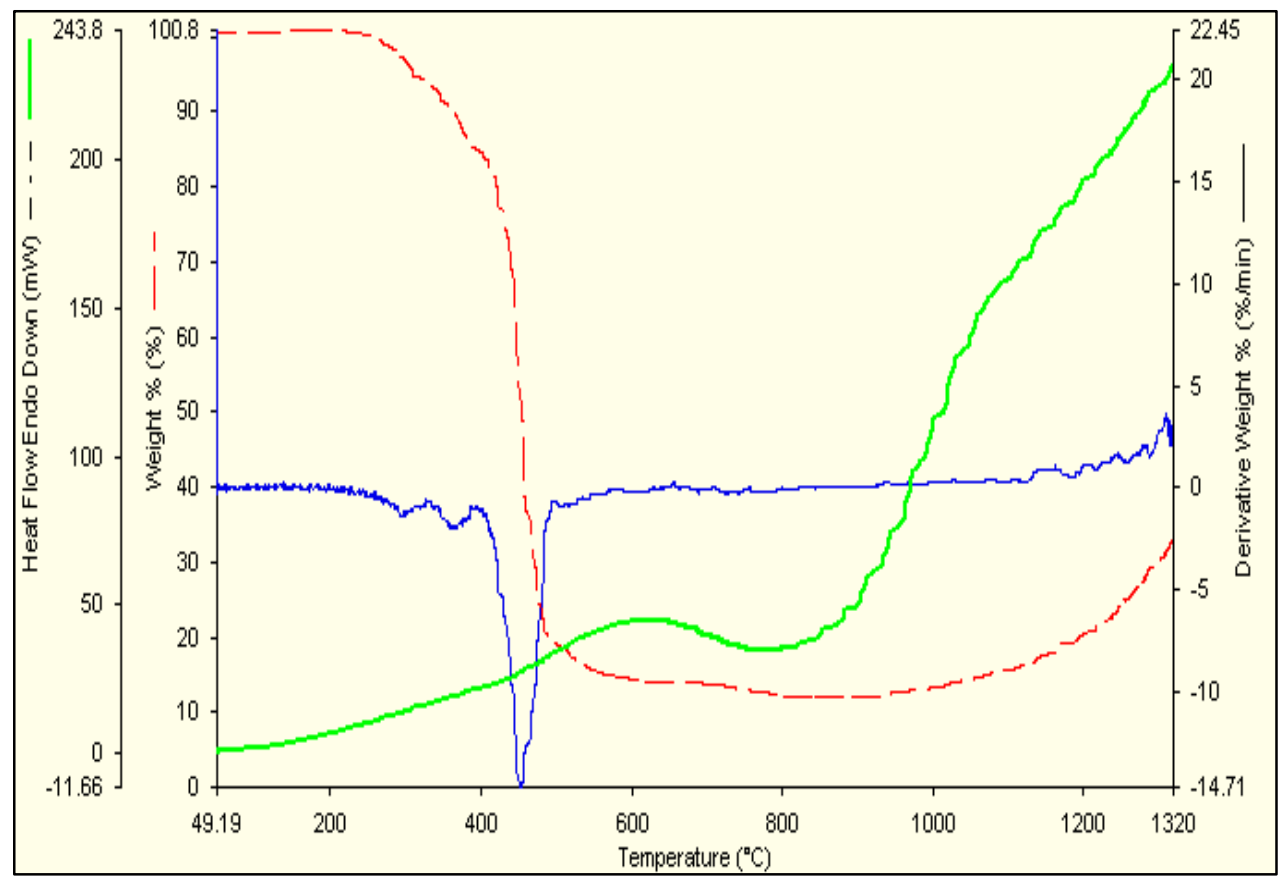

Şekil 6. Badem kabuğu ile immobilize edilmiş Amberlit XAD-4 kolon dolgu maddesinin termogravimetrik analiz (TG/DTA) Grafiği

Tablo 4. Badem kabuğu ile immobilize edilmiş Amberlit XAD-4 kolon dolgu maddesinin BET analizi Yüzey Alanı

Tek Nokta Yüzey Alanı, P/Po = 0,349514807: 612,5222 $\mathrm{m}^{2} / \mathrm{g}$

BET Yüzey Alanı: 396,9105 m²/g

\begin{tabular}{l}
\hline Gözenek Hacmi \\
\hline Az Gözenekli Tek Noktalı Adsorpsiyonda Toplam Gözenek Hacmi : 1185,563 $\AA$ \\
\hline Gözenek Boyutu
\end{tabular}

Adsorpsiyonun Ortalama Gözenek Genişliği (4V/A BET ile) :104,2970 ${ }^{\circ} \mathrm{A}$

\subsection{Kadmiyum İyonu İçin Önderiştirme Prosedürü}

Badem kabuğuna immobilize edilmiş amberlit XAD-4 ile dolgulu kolonlar tampon çözeltiler yardımıyla çalışılacak pH'ya ayarlanarak kolonların şartlanması sağlanmıştır. Farklı derişimlerde Cd (II) içeren model çözelti belli bir akış hızı ile kolondan geçirilmiştir. Kolonda tutulan metal iyonu $\mathrm{HCl}$ kullanarak elüe edilmiştir. Ancak elüent tipi ve miktarı aşamasından sonra en uygun eluentin $\mathrm{HNO}_{3}$ olduğu saptanmıştır.Eser analizde kullanılan zenginleştirme yöntemlerinin değerlendirilmesinde istenilen eser elementin ortamdan ayrılmasının ölçüsü olan geri kazanma verimi, R'dir. Geri kazanma verimi aşağıdaki formül ile hesaplanmıştır. $\% \mathrm{R}=\frac{Q}{Q_{0}} x 100$ burada; derişimi,
Q: Zenginleştirme sonrası analiz elementinin derişimi,

İdeal olan, R değerinin \%100 olmasıdır. Ancak uygulamada \% 99'dan daha büyük geri kazanma verimine ulaşmak her zaman mümkün değildir [46].

\section{Bulgular}

\subsection{Ph'ın Geri Kazanım Verimi Üzerine Etkisi}

Biyosorpsiyon çalışmaları için kullanılan en önemli parametre çözeltinin başlangıç pH'sıdır [47]. Çözelti pH'1, metallerin çözelti kimyasını, hücre duvarı üzerindeki işlevsel grupların (karboksilat, fosfat ve amino grupları) aktivitesini ve bağlanma yeri için metalik iyonların rekabetini güçlü bir şekilde etkimektedir. $\mathrm{Bu}$ aşamada $0,25 \mathrm{~g}$ badem kabuğu ve 1,0 g Amberlite XAD-4'ten oluşan kolondan $\mathrm{pH}=$ 3,0-10,0 aralığında 2 ppm $50 \mathrm{~mL}$ Cd çözeltisi geçirilmiş ve elde edilen sonuçlar Şekil 7'de verilmiştir. 


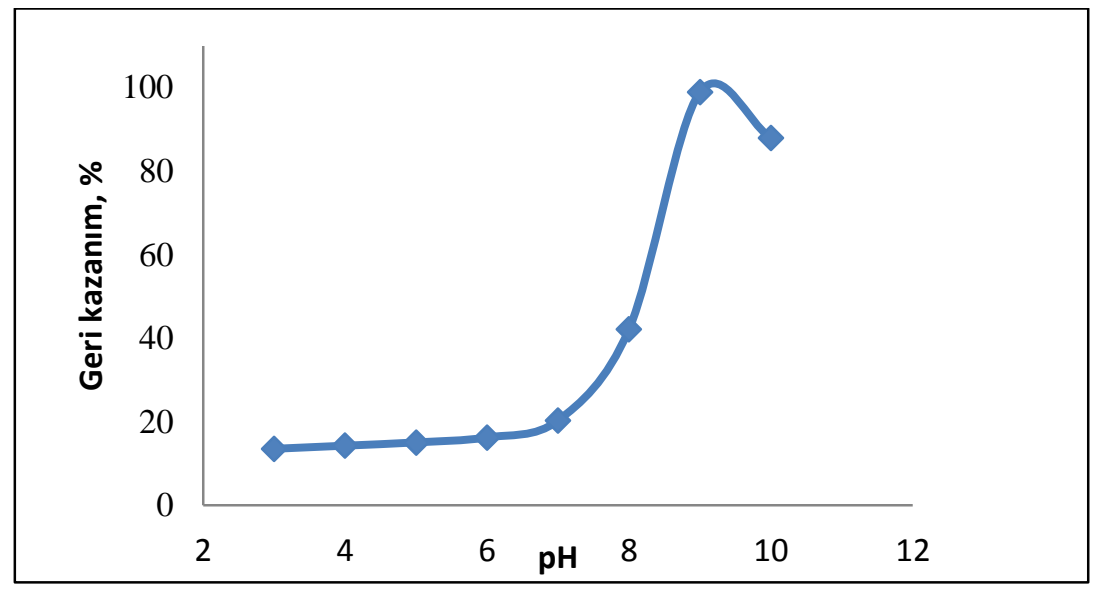

Şekil 7. Geri kazanım değerlerine $\mathrm{pH}$ etkisi

Şekil 7 incelendiğinde, Çözeltideki $\mathrm{Cd}^{2+}$ iyonunun pH 2,0'da geri kazanım verimi \% 13.53 olarak bulunmuş ve çözelti pH'sı 2,0'den 9,0'a yükseldiğinde artmıştır. $\mathrm{pH}$ değeri 9,0 olan $\mathrm{Cd}^{2+}$ iyononun çözeltiden uzaklaştırma oranı \% 98,97 bulunmuştur. $\mathrm{Bu}$ verilerden yararlanılarak badem kabuğu için optimum geri kazanma veriminin en uygun $\mathrm{pH}$ değeri 9,0 olarak seçilmiştir.

\section{2. Örnek akış hızının geri kazanım verimi üzerine etkisi}

Örnek akış hızının geri kazanma verimi üzerine etkisini incelemek amaciyla badem kabuğuna immobilize edilmiş Amberlit XAD-4 karışımından geçirilen $50 \mathrm{~mL}$ hacmindeki Cd iyonu, akış hızı 1-7 $\mathrm{mL} /$ dakika aralığında olacak şekilde peristaltik pompa yardımıyla kolondan geçirilmiştir. Elde edilen sonuçlar Şekil 8'de verilmiştir.

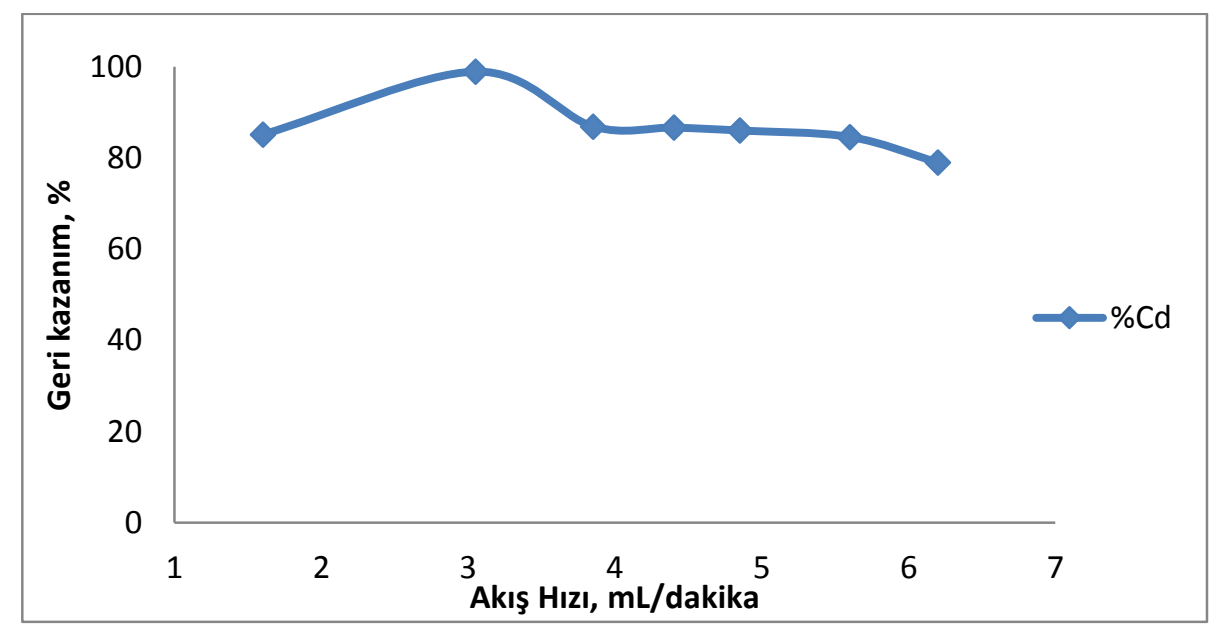

Şekil 8 Geri kazanım değerlerine örnek akış hızının etkisi

Şekil 8 incelendiğinde en yüksek akış hızı 3,05 $\mathrm{mL} /$ dakika olduğu $\mathrm{Cd}^{2+}$ iyononun geri kazanma verimi \% 98,87 olarak bulunmuştur. Bununla birlikte, metal çözeltilerin akış hızı, 3,05 mL/dakika üstünde, analitlerin geri kazanımının azaldığı görülmüştür. Bundan sonraki çalışmaların tamamı, çözeltilerin akış hızı, 3,05 mL/dakika olacak şekilde yapılmıştır.

\subsection{Biyosorbent miktarının geri kazanım verimi üzerine etkisi}

Biyosorbent miktarının katı faz ekstraksiyonu üzerine etkisi incelenmiştir. Bu amaç için 0,150, $0,250,0,300,0,350,0,400,0,450 \mathrm{~g}$ biyosorbent tartılarak belli aşamalar uygulanıp badem kabuğu immobilize edilmiş Amberlit XAD-4 karışımları kolona yerleştirilmiştir. Daha sonra hazırlanmış olan 2 ppm Cd pH 9,0'da 3,05 mL/dakika akış hızıyla geçirilmiştir. Sonra, biyosorbente tutunan analit, 5 $\mathrm{mL}$ 0,5 $\mathrm{M} \mathrm{HCl}$ kolondan geçirilerek geri alınmıştır. Daha sonra elde edilen çözeltideki metal iyonu AAS ile tayin edilmiş ve elde edilen sonuçlar Şekil 9'da verilmiştir. 


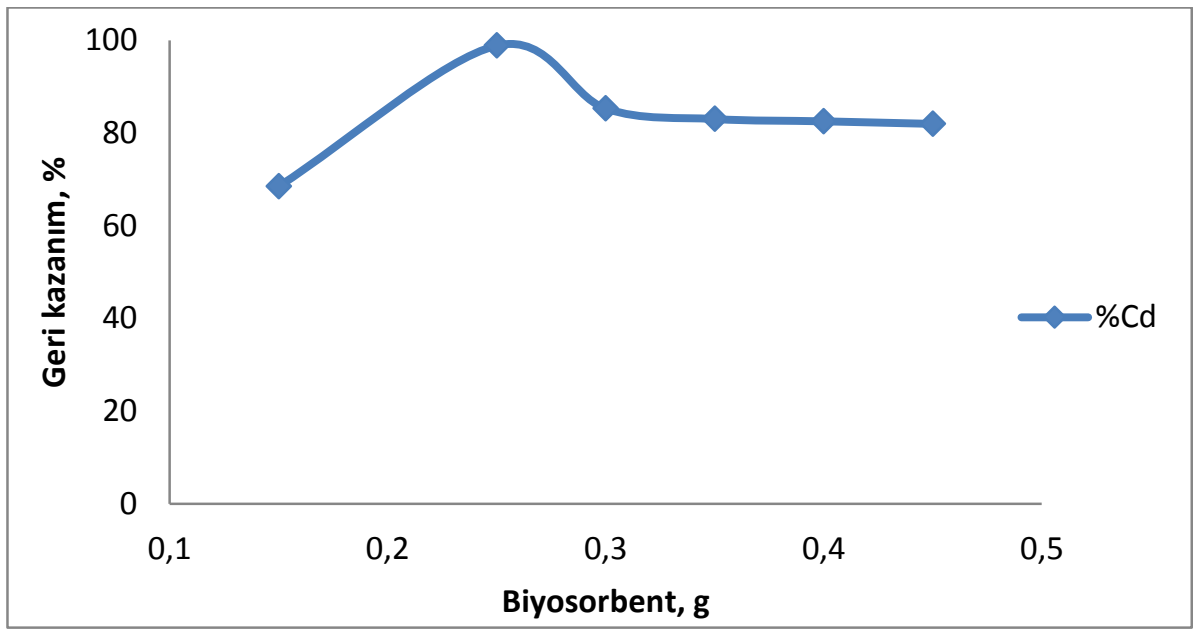

Şekil 9. Geri kazanım değerlerine biyosorbent etkisi

Şekil 9 incelendiğinde Cd için optimum biyosorbent miktarı 0,25 gram olarak tespit edilmiştir.

\subsection{Adsorbent Miktarının Geri Kazanım Verimi Üzerine Etkisi}

Adsorbent olarak Amberlit XAD-4 miktarının katı faz ekstraksiyonu üzerine etkisi incelenmiştir. Adsorbentin geri kazanma verimine etkisini incelemek için hazırlanan katı fazdan biyosorbent olarak 0,25 gram badem kabuğu alınıp 0,25, 0,50, $0,75,1,0,1,5,2,0$ gram adsorbent olarak Amberlit
XAD-4 tartılarak her biri için ayrı ayrı aşamalardan geçirilip hazırlanan karışım kolonlara yerleştirilmiştir. Daha sonra hazırlanan 2 ppm Cd iyonu en uygun pH'ya ayarlanıp en uygun akış hızında kolondan geçirilmiştir. Sonra, adsorbente tutunan analit, $5 \mathrm{~mL}$ 0,5 $\mathrm{M} \mathrm{HCl}$ kolondan geçirilerek geri alınmıştır. Daha sonra geri alınan çözeltideki metal iyonları AAS ile tayin edilmiş ve elde edilen sonuçlar Şekil 10'da verilmiştir.

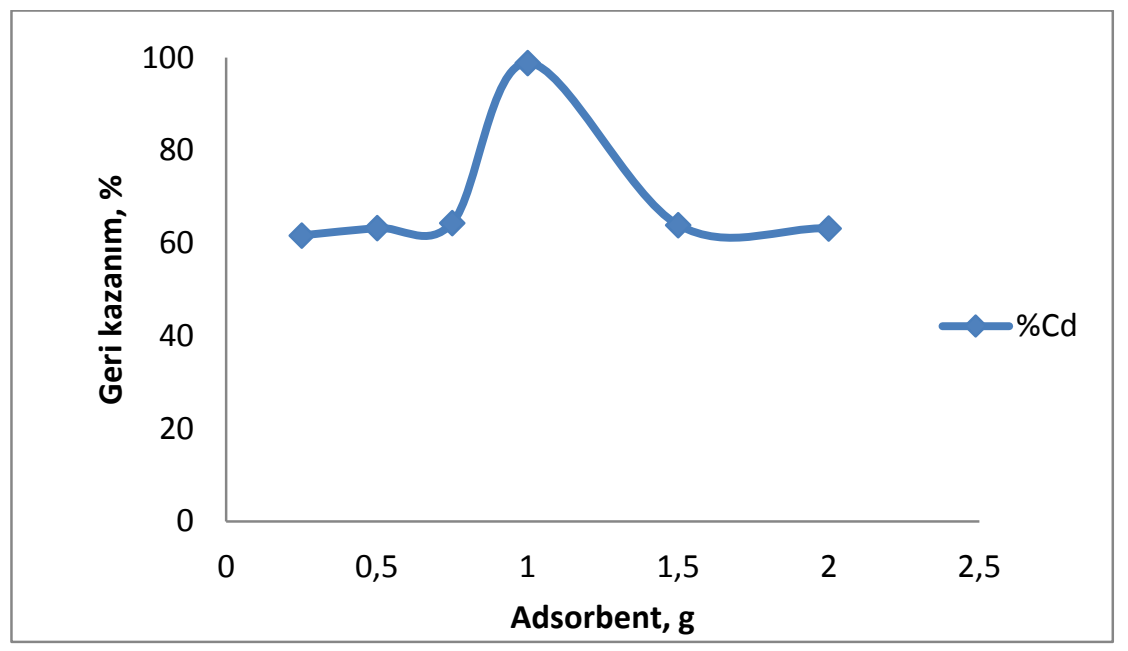

Şekil 10. Geri kazanım değerlerine adsorbent etkisi

Şekil 10 incelendiğinde Cd için optimum adsorbente miktarı 1,0 gram Amberlit XAD-4 olarak tespit edilmiştir.

\section{5. Örnek Hacminin Geri Kazanım Verimi Üzerine Etkisi}

Badem kabuğu immobilize edilmiş Amberlit XAD4 karışımından geçirilen örnek çözelti hacminin geri kazanım verimine etkisini araştırmak amacıyla, ayrı ayrı Cd(II) için 2ppm içeren çözeltiden, 25, 50, 100,
200, 300, 400 mL’lik örnek çözeltiler optimum koşullarda kolondan geçirilmiştir. Kolonda tutunan metal iyonu $5 \mathrm{~mL} 0,5 \mathrm{M} \mathrm{HCl}$ çözeltisi ile elüe edilmiştir. Elüe edilen çözeltideki metal iyonu AAS ile tayin edilmiş ve elde edilen sonuçlar Şekil 11'de verilmiştir. 


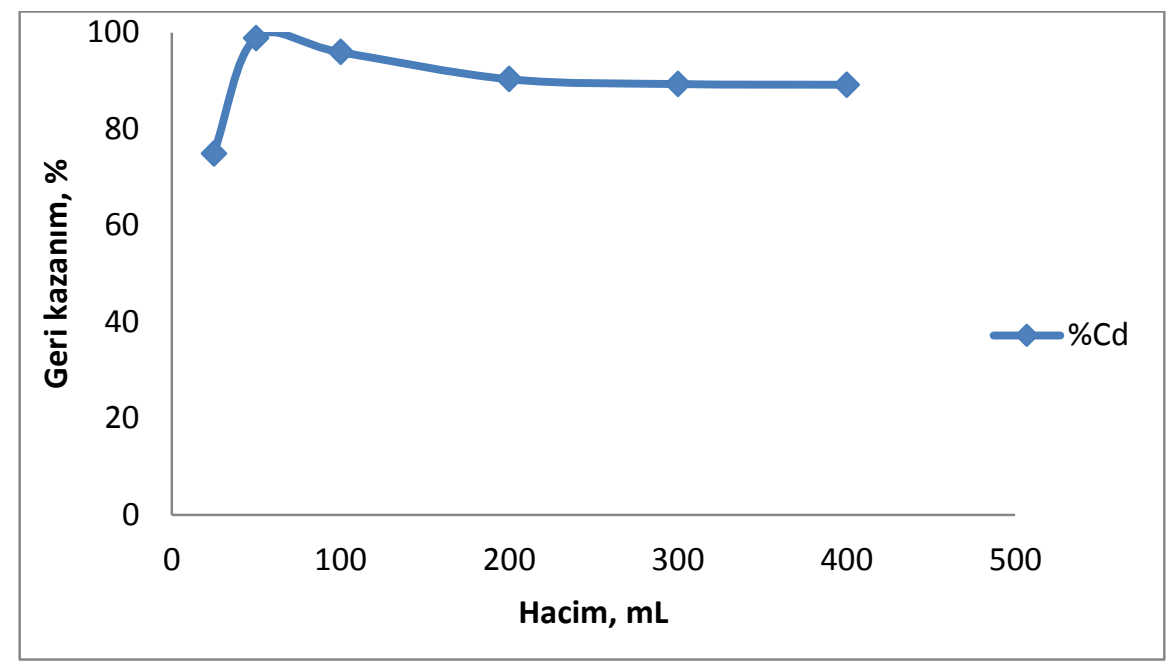

Şekil 11. Geri kazanım değerlerine örnek hacminin etkisi

Şekil 11 incelendiğinde en uygun hacim Cd için $50 \mathrm{~mL}$ olduğu görülmüştür.

\subsection{Elüent Türü ve Derişiminin Geri} Kazanım Verimi Üzerine Etkisi

Badem kabuğu immobilize edilmiş Amberlit XAD4 karışımından oluşan dolgulu kolonda tutunan Cd(II) iyonunun kantitatif olarak geri kazanılması için uygun bir elüe edicinin kullanılması gerekir. $\mathrm{Bu}$ amaç için pH 9,0, akış hızı 3,05 mL/dakika, 0,25 g badem kabuğu, 1,0 g Amberlit XAD-4, $50 \mathrm{~mL}$ hacmindeki örnek çözeltiler kolondan geçirilmiştir. $\mathrm{Bu}$ amaç için $\mathrm{HCl}$ ve $\mathrm{HNO}_{3}$ kullanılmış olup elde sonuçlar Tablo 5 'te verilmiştir.

Tablo 5. Elüent tipi ve miktarının geri kazanıma etkisi

\begin{tabular}{cccc}
\hline $\begin{array}{c}\text { Elüasyon Çözelti } \\
\text { Türü }\end{array}$ & $\begin{array}{c}\text { Elüasyon Çözelti } \\
\text { Derişimi (mol/L) }\end{array}$ & $\begin{array}{c}\text { Elüasyon Çözelti } \\
\text { Hacmi }(\mathbf{m L})\end{array}$ & Geri Kazanım Verimi (\%) \\
\hline & 0,5 & 5 & Cd(II) \\
\hline \multirow{2}{*}{$\mathrm{HCl}$} & 1,0 & 5 & 92,30 \\
& 1,5 & 5 & 95,07 \\
& 2,0 & 5 & 94,56 \\
& 0.5 & 5 & 93,37 \\
\hline & 1.0 & 5 & 92,27 \\
$\mathrm{HNO}_{3}$ & 1.5 & 5 & 93,68 \\
& 2,0 & 5 & 98,35 \\
& & 5 & 98,31 \\
\hline
\end{tabular}

Tablo 5 incelendiğinde \%98,35 Cd iyonunun geri kazanım verimi ile elüent türü ve elüent derişimi için 1,5 M $\mathrm{HNO}_{3}$ olduğu görülmüştür.

\subsection{Yabancı İyonun Geri Kazanım Verimi Üzerine Etkisi}

Gerçek örneklerde eser metallerin tayin edilmesi yabancı iyonların matriks etkisi yapmasından dolayı zorlaşmaktadır [35]. Matriks etkisini incelemek için su örneklerinde yer alan $\mathrm{Na}^{+}, \mathrm{Cl}^{-}, \mathrm{Mn}^{2+}, \mathrm{Mg}^{2+}, \mathrm{Ca}^{2+}$,
$\mathrm{F}^{-}$iyonlarının Cd (II) analit iyonlarının geri kazanım değerlerine etkisi incelenmiştir. Farklı derişimlerde bu iyonların yer aldığı model çözeltilere geliştirilen yöntem uygulanıp geri kazanım değerleri incelenmiştir. Elde edilen sonuçlar Tablo 6'da verilmiştir. 
Tablo 6. Yabancı iyonların geri kazanıma etkisi

\begin{tabular}{llcc}
\hline İyon & Eklenen Tuzu & Derişim (mg/L) & Cd(II) için Geri Kazanım, (\%) \\
\hline $\mathrm{Na}^{+}$ & $\mathrm{NaCI}$ & 10000 & $98,84 \pm 1,26$ \\
$\mathrm{Cl}^{-}$ & $\mathrm{BaCl}_{2} \cdot \mathrm{H}_{2} \mathrm{O}$ & 20 & $85,82 \pm 1,96$ \\
$\mathrm{Mn}^{2+}$ & $\mathrm{MnSO}_{4} \cdot \mathrm{H}_{2} \mathrm{O}$ & 50 & $82,89 \pm 1,78$ \\
$\mathrm{Mg}^{2+}$ & $\mathrm{Mg}^{2+}\left(\mathrm{NO}_{3}\right)_{3} 6 \mathrm{H}_{2} \mathrm{O}$ & 5000 & $85,69 \pm 1,87$ \\
$\mathrm{Ca}^{2+}$ & $\mathrm{CaCl}_{2} \cdot 2 \mathrm{H}_{2} \mathrm{O}$ & 3000 & $83,50 \pm 1,98$ \\
$\mathrm{~F}^{-}$ & $\mathrm{KF}$ & 1000 & $98,38 \pm 1,65$ \\
\hline
\end{tabular}

Tablo 6 incelendiğinde $\mathrm{Na}$ ve $\mathrm{F}$ iyonlarının geri kazanım verimi üzerinde bir etkilerinin olmadığı, diğer iyonlarının ise geri kazanım verimi üzerinde negatif yönünde etkileri olduğu görülmüştür. Belirlenen hata, değerin \% 2'yi geçmediğini göstermiştir ve bu hata değeri AAS belirleme yöntemleri [48] ile belirlenmiştir.

\subsection{Kolonun Tekrarlanabilirliğ $i$}

$\mathrm{Bu}$ tür zenginleştirme çalışmalarında absorbanın tekrar kullanılabilirliği çok büyük önem arz etmektedir. Katı faz ekstraksiyonu (SPE) kolonunun kararlılığını test etmek için $50 \mathrm{~mL}$ 2ppm Cd çözeltisi badem kabuğu immobilize edilmiş Amberlit XAD-4 kolon dolgu maddesi için belirlenen optimum koşullarda 10 defa geçirilmiştir. Biyolojik olarak absorbe edilen $\mathrm{Cd}^{2+}$ iyonları, 5,0 $\mathrm{mL} \mathrm{1,5} \mathrm{mol} \mathrm{L} \mathrm{L}^{-1}$ $\mathrm{HNO}_{3}$ çözeltisi ile elüe edilmiştir. Elde dilen sonuçlar Şekil 12'de verilmiştir.

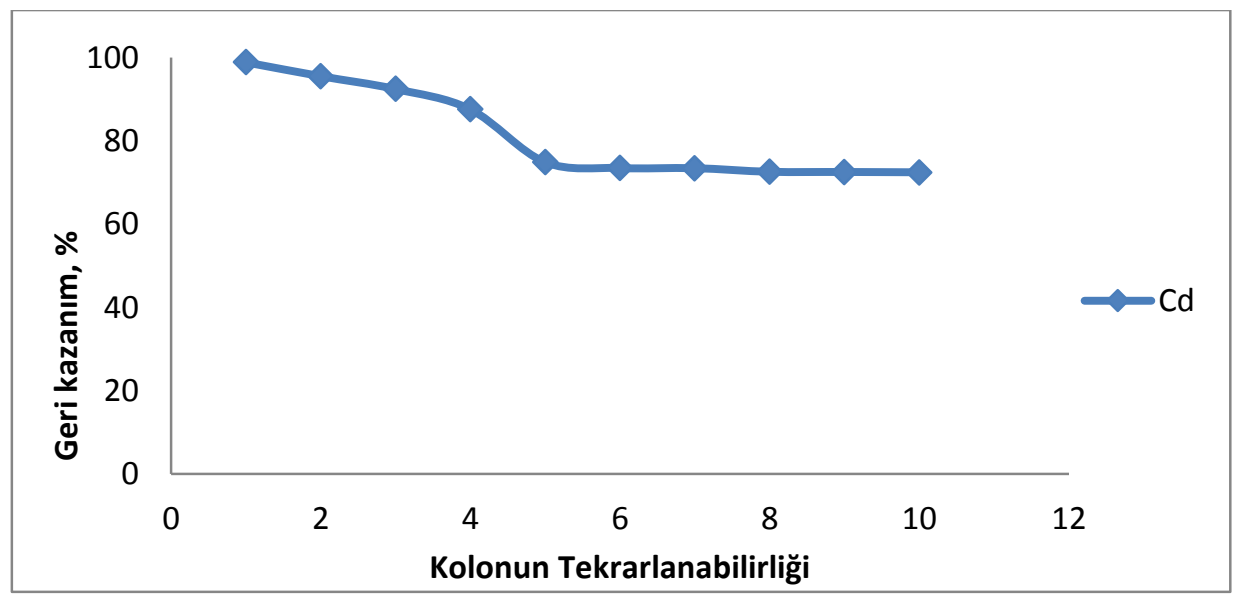

Şekil 12. Kolonun tekrarlanabilirliği

Şekil 12 incelendiğinde, kolonun yaklaşık ilk beș (>\%89) kullanımdan sonra verimin azaldığı ve daha sonra sabit kaldığı görülmüştür. Kolonun on kez kullanımı sonucu ortalama geri kazanım verimi $>\% 81$ olmuştur.

\subsection{Gözlenebilme (LOD) Ve Tayin Sınırı (LOQ)}

Analit iyonlarının gözlenebilme sınırı tayini için 12 paralel kör örneğe geliştirilen yöntem uygulanmıştır. Kör değerlerin standart sapmasının üç katı ve on katı esas alan gözlenebilme sinırı değerleri zenginleştirme faktörüne bölünerek hesaplanmıştır. Elde edilen değerler Tablo 7'de verilmiştir [8].
Tablo 7. Gözlenebilme sınırı ve tayin sınırı

\begin{tabular}{cccc}
\hline Element & $\begin{array}{c}\text { LOD } \\
(\mathbf{p p b})\end{array}$ & LOQ (ppb) \\
\hline $\mathrm{Cd}(\mathrm{II})$ & 5,1 & 17,2 \\
\hline $\begin{array}{l}\text { 3.10. Analitik } \\
\text { Uygulanabilirliği }\end{array}$ & Özellikler & ve & Yöntemin
\end{tabular}

Optimum zenginleştirme şartları belirlendikten sonra, geliştirilen yöntemin kesinliği incelenmiştir. Elde edilen sonuçlar Tablo 8'de verilmiştir. 
Tablo 8. Kesinlik Sonuçları

\begin{tabular}{lcc}
\hline Element & $\begin{array}{c}(\mathbf{\%}) \mathbf{R} \pm \mathbf{t} \\
\mathbf{S} / \sqrt{ } \mathbf{N}\end{array}$ & $\begin{array}{c}\text { \% Bağıl Standart } \\
\text { Sapma }\end{array}$ \\
\hline $\mathrm{Cd}$ & $98,87 \pm 1,85$ & 3,21 \\
& \\
\hline \multicolumn{2}{c}{ \% 95 Güven Seviyesinde N=3 BSS: Bağıl } \\
\multicolumn{2}{l}{ Standart Sapma }
\end{tabular}

Bağıl standart sapma (RSD) $\mathrm{Cd}^{2}+$ için 3,21 olarak belirlenmiştir. Regresyon katsayısı, kadmiyum için 0,9975 olarak tespit edilmiştir. Ön zenginleştirme faktörü kadmiyum için 10 kat olarak saptanmıştır. Geliştirilen yöntem, sertifikalı referans (BCR-670 Aquatic Plant) örneğine uygulanmıştır. Elde edilen sonuçlar Tablo 9'da gösterilmiştir.

Tablo 9. Geliştirilen yöntemin sertifikalı referans maddeye (BCR-670 Aquatic Plant Sample) uygulanması

\begin{tabular}{lcc}
\hline Sertifikalı Referans & \multicolumn{2}{c}{ Cd $^{2+}$} \\
\cline { 2 - 3 } Standart Madde & Sertifikalı Değer & Bulunan Değer \\
\hline BCR-670 Aquatic Plant & $75,50 \pm 2,50$ & $73,70 \pm 2,30$ \\
\hline$\% 95$ güvenle 3 değerin ortalamasıdır. $\mathrm{x} \pm \mathrm{ts} / \sqrt{\mathrm{N}})$ &
\end{tabular}

Tablo 9 incelendiğinde elde edilen sonuçların sertifikalı referans madde sonuçları ile tutarlı olduğu görülmüştür. Bu yöntem, Siirt atık suyuna, Siirt musluk suyu, Van gölü suyuna, Tuzkuyusu tuzlu suyu ve Billoris kaplica suyu örneklerine

Tablo 10. Gerçek numunelere uygulama

\begin{tabular}{lc}
\hline Su Örneği & Cd için Geri Kazanım, \% \\
\hline Atık Su & T.E \\
Van Gölü suyu & T.E \\
Musluk Suyu & T.E \\
Tuzkuyusu & T.E \\
Billoris Suyu & T.E \\
\hline
\end{tabular}

Sonuçlar \% 95 güven seviyesi ile 3 ölçümün ortalamasıdır $(\mathrm{x} \pm \mathrm{ts} / \sqrt{ } \mathrm{N})$, T.E: Tespit Edilemedi.

\section{Değerlendirme ve Sonuç}

Bu çalışmada, biyosorbent olarak badem kabuğuna immobilize edilmiş Amberlit XAD-4, polimerinin üzerine $\mathrm{Cd}(\mathrm{II})$ iyonunun katı faz ekstraksiyonu yöntemi ile zenginleştirme şartları araştırılmıştır. Cd iyonu için $\mathrm{pH}$ 9, Akış Hızı 3,05 mL/dakika, biyosorbent (badem kabuğu) 0,250 gram, adsorbent (Amberlit XAD-4) 1,00 gram, hacim $50 \mathrm{ml}$, elüent 1,5 $\mathrm{M} \mathrm{HNO}_{3}$ gibi optimum koşullar belirlenmiştir. Geliştirilen yöntem ile Cd iyonu 10 kat zenginleşme sağlanmıştır. Cd için gözlenebilme sınırı (LOD) 5,1, tayin sınırı (LOQ) 17,2 ppb olarak belirlenmiştir. Yöntemin optimum şartlarda 3 tekrar deneyi için geri kazanma veriminin tekrarlanabilirliği (kesinliği), \% 95 güven seviyesinde $\mathrm{Cd}$ için \% 98,87 $\pm 1,85$ olarak bulunmuştur. Ayrıca \% 95 güven seviyesinde, 3 tekrar deneyi için \% bağıl standart sapma değeri \%3,21 olarak bulunmuştur. Geliştirilen yöntem çevre örneklerine uygulanmış, ancak kadmiyum iyonu tespit edilememiştir. Biyosorbent olarak badem kabuğu kullanılan diğer çalışmaların metal verimiyle kıyas yapıldığında (Cr (VI) için \% 55.00 [9], $\mathrm{Pb}$ için \% 68.00 [10] ve \% 80 [12], Cd için $\%$ 34,64 [11] ve \% 74,8 [12]) bu çalışmanın daha yüksek geri kazanım verimiyle metal iyonunun zenginleştiği görülmüştür. uygulanmış olup elde edilen sonuçlar Tablo.10'da verilmiştir. Tablo 10 incelendiğinde yöntemin çevre örneklerine uygulanışından sonuç alınamadığı görülmüştür.

\section{Teşekkür}

Bu çalışma Siirt Üniversitesi Bilimsel Araştırma Projeleri Birimi tarafından 2015-SİÜFEB-34 kodlu araştırma projesi ile desteklenmiştir.

\section{Kaynaklar}

[1] S. D. Fadime Nazlı Dinçer Kaya, Orhan Atakol, "Katı Faz Ekstraksiyonu ile Bakır ve Nikelin Önderiştirilmesinde ONNO ve ONO Tipi Schiff Bazlarının Karşılaştırılması," vol. 9, no. 1, pp. 176$185,2014$.

[2] S. Sigma-Aldrich, "Guide to Solid Phase Extraction - bulletin 910,” Bull. 910, p. , 1998.

[3] S. Dogan, F. Nazl, D. Kaya, and O. Atakol, "Enrichment of copper and nickel with solid phase extraction using multiwalled carbon nanotubes modified with Schiff bases," vol. 7319, no. July 2016, 2015.

[4] M. Ghaedi, M. Montazerozohori, A. Hekmati, and M. Roosta, "Solid phase extraction of heavy metals on chemically modified silica-gel with 2-(3silylpropylimino) methyl)-5-bromophenol in food samples," Int. J. Environ. Anal. Chem., vol. 93, no. 8, pp. 843-857, 2013. 
[5] S. E. SOYSAL, "Katı Destek Üzerine İmmobilize Edilmiş Bazı Bakteriler İle Ağır Metal İyonlarının Ayırma ve Deriştirme Şartlarının Araştırılması," ADNAN MENDERES ÜNIVERSITTESİ, 2010.

[6] S. Eşer, "Salinivibrio Sharmensis Tutturulmuş Amberlit XAD- 4 Kullanarak Kat1 Faz Ekstraksiyonu İle Cd ( II ) Ve Ni ( II ) İyonlarının FAAS İle Tayini," Dicle Üniversitesi, 2012.

[7] S. D. Çekiç, H. Filik, and R. Apak, "Use of an o-aminobenzoic acid-functionalized XAD-4 copolymer resin for the separation and preconcentration of heavy metal(II) ions," Anal. Chim. Acta, vol. 505, no. 1, pp. 15-24, 2004.

[8] N. Erdoğan, "Birlikte Çöktürme İle Eser Düzeydeki Bazı Metal İyonlarının Zenginleştirilmesi Ve AAS İle Tayinleri," Erciyes Üniversitesi, Turkey, 2005.

[9] E. Pehlivan and T. Altun, "Biosorption of chromium(VI) ion from aqueous solutions using walnut, hazelnut and almond shell," J. Hazard. Mater., vol. 155, no. 1-2, pp. 378-384, 2008.

[10] E. Pehlivan, T. Altun, S. Cetin, and M. Iqbal Bhanger, "Lead sorption by waste biomass of hazelnut and almond shell," J. Hazard. Mater., vol. 167, no. 1-3, pp. 1203-1208, 2009.

[11] Y. Bulut and Z. Tez, "Adsorption studies on ground shells of hazelnut and almond," J. Hazard. Mater., vol. 149, no. 1, pp. 35-41, 2007.

[12] M. Kazemipour, M. Ansari, S. Tajrobehkar, M. Majdzadeh, and H. R. Kermani, "Removal of lead, cadmium, zinc, and copper from industrial wastewater by carbon developed from walnut, hazelnut, almond, pistachio shell, and apricot stone,' J. Hazard. Mater., vol. 150, no. 2, pp. 322-327, 2008.

[13] A. Ronda, M. A. Martín-Lara, E. Dionisio, G. Blázquez, and M. Calero, "Effect of lead in biosorption of copper by almond shell," J. Taiwan Inst. Chem. Eng., vol. 44, no. 3, pp. 466-473, 2013. [14] A. H. Aydin, Y. Bulut, and Ö. Yavuz, "Acid dyes removal using low cost adsorbents," vol. 21, no. 1, pp. 97-104, 2004.

[15] A. Ahmad, J. A. Siddique, M. A. Laskar, R. Kumar, S. H. Mohd-Setapar, A. Khatoon, and R. A. Shiekh, "New generation Amberlite XAD resin for the removal of metal ions: A review," Journal of Environmental Sciences (China), vol. 31. Elsevier B.V., pp. 104-123, 2015.

[16] M. Kumar, D. P. S. Rathore, and A. K. Singh, "Metal ion enrichment with Amberlite XAD-2 functionalized with Tiron: analytical applications," Analyst, vol. 125, no. 6, pp. 1221-1226, 2000.

[17] D. Kara, A. Fisher, and S. J. Hill, "Determination of trace heavy metals in soil and sediments by atomic spectrometry following preconcentration with Schiff bases on Amberlite XAD-4," J. Hazard. Mater., vol. 165, no. 1-3, pp. 1165-1169, 2009.
[18] A. Ahmad, "Preparation, Characterization of a Novel Chelating Resin Functionalized with o Hydroxybenzamide and Its Application for Preconcentration of Trace Metal Ions," CleanSoil,Air,Water, vol. 40, no. 1, pp. 54-65, 2012.

[19] A. Islam, A. Ahmad, and M. A. Laskar, "Characterization of a Chelating Resin Functionalized via Azo Spacer and Its Analytical Applicability for the Determination of Trace Metal Ions in Real Matrices," J. Appl. Polym. Sci., vol. 123, pp. 3448-3458, 2012.

[20] P. K. Tewari and A. K. Singh, "Preconcentration of lead with Amberlite XAD-2 and Amberlite XAD-7 based chelating resins for its determination by flame atomic absorption spectrometry," Talanta, vol. 56, no. 4, pp. 735-744, 2002.

[21] S. Özdemir, V. Okumuş, E. Klnç, H. Bilgetekin, A. Dündar, and B. Ziyadanogullar, "Pleurotus eryngii immobilized Amberlite XAD-16 as a solid-phase biosorbent for preconcentrations of $\mathrm{Cd} 2$ and $\mathrm{Co} 2$ and their determination by ICP-OES," Talanta, vol. 99, pp. 502-506, 2012.

[22] P. Kalny, Z. Fijałek, A. Daszczuk, and P. Ostapczuk, "Determination of selected microelements in polish herbs and their infusions," Sci. Total Environ., vol. 381, no. 1-3, pp. 99-104, 2007.

[23] I. Gogoasa, J. Violeta, A. L. Maria, V. Ariana, R. Maria, S. Alda, S. Claudia, B. D. Maria, and I. Gergen, "Mineral Content of Some Medicinal Herbs," vol. 17, no. 4, pp. 65-67, 2013.

[24] E. L. and D. M. N. İ. Soylak M, "Analize Yaklaşım ve Karasu , Sarmısaklı Çayı Kızılırmak Nehrindeki $\mathrm{Pb}, \mathrm{Cu}, \mathrm{Ni}, \mathrm{Co}$ ve $\mathrm{Cd}$ Kirliliğinin Araştırılması Approaches To Analysis and Investigation of $\mathrm{Pb}, \mathrm{Cu}, \mathrm{Ni}, \mathrm{Co}$, and Cd Pollution in Karasu , Sarmısaklı Çayı and Kızılırmak Rivers," pp. 21-30, 2009.

[25] R. A. Gil, S. Cerutti, J. A. Gásquez, R. A. Olsina, and L. D. Martinez, "Preconcentration and speciation of chromium in drinking water samples by coupling of on-line sorption on activated carbon to ETAAS determination," Talanta, vol. 68, no. 4, pp. 1065-1070, 2006.

[26] A. O. Martins, E. L. Da Silva, M. C. M. Laranjeira, and V. T. De Fávere, "Application of chitosan functionalized with 8-hydroxyquinoline: Determination of lead by flow injection flame atomic absorption spectrometry," Microchim. Acta, vol. 150, no. 1, pp. 27-33, 2005.

[27] A. Ahmad, A. Khatoon, M. A. Laskar, A. Islam, A. W. Mohammad, and N. L. Yong, "Use of 2-hydroxy-3-methoxybenzaldehyde functionalized amberlite xad-16 for preconcentration and determination of trace metal ions by flame atomic absorption spectrometry," Der Pharma Chem., vol. 5, no. 1, pp. 12-23, 2013. 
[28] M. J. Marqués, A. Morales-Rubio, A. Salvador, and M. De la Guardia, "Chromium speciation using activated alumina microcolumns and sequential injection analysis-flame atomic absorption spectrometry," Talanta, vol. 53, no. 6, pp. 1229-1239, 2001.

[29] A. Islam, A. Ahmad, M. A. Laskar, J. A. Siddique, M. A. Laskar, R. Kumar, S. H. MohdSetapar, A. Khatoon, R. A. Shiekh, A. Islam, M. A. Laskar, A. Ahmad, A. Khatoon, M. A. Laskar, A. Islam, A. W. Mohammad, and N. L. Yong, "Newgeneration AmberliteXADresin for the removal of metal ions: A review," J. Appl. Polym. Sci., vol. 5, no. 1, pp. 12-23, 2013.

[30] D. Kara, "Evaluation of trace metal concentrations in some herbs and herbal teas by principal component analysis," Food Chem., vol. 114, no. 1, pp. 347-354, 2009.

[31] M. Soylak and N. D. Erdogan, “Copper(II)rubeanic acid coprecipitation system for separationpreconcentration of trace metal ions in environmental samples for their flame atomic absorption spectrometric determinations," J. Hazard. Mater., vol. 137, no. 2, pp. 1035-1041, 2006.

[32] C. Karadaş and D. Kara, "On-line preconcentration and determination of trace elements in waters and reference cereal materials by flow injection - FAAS using newly synthesized 8hydroxy-2-quinoline carboxaldehyde functionalized Amberlite XAD-4," J. Food Compos. Anal., vol. 32, no. 1, pp. 90-98, 2013.

[33] R. G. Pellerano, M. A. Uñates, M. A. Cantarelli, J. M. Camiña, and E. J. Marchevsky, "Analysis of trace elements in multifloral Argentine honeys and their classification according to provenance," Food Chem., vol. 134, no. 1, pp. 578582, 2012.

[34] Ş. Tokalıŏlu, "Determination of trace elements in commonly consumed medicinal herbs by ICP-MS and multivariate analysis," Food Chem., vol. 134, no. 4, pp. 2504-2508, 2012.

[35] M. Alan, D. Kara, and A. Fisher, "Preconcentration of Heavy Metals and Matrix Elimination using Silica Gel Chemically Modified with 2,3-Dihydroxybenzaldehyde," Sep. Sci. Technol., vol. 42, no. 4, pp. 879-895, 2007.

[36] I. Rodushkin and T. Ruth, "Determination of Trace Metals in Estuarine and Sea-water Reference Materials by High Resolution Inductively Coupled Plasma Mass Spectrometry," J. Anal. At. Spectrom., vol. 12, no. 10, pp. 1181-1185, 1997.

[37] I. Dolak, I. Tegin, R. Guzel, and R. Ziyadanogullari, "Removal and preconcentration of $\mathrm{Pb}(\mathrm{II}), \mathrm{Cr}(\mathrm{III}), \mathrm{Cr}(\mathrm{VI})$ from the aqueous solution and speciation of $\mathrm{Cr}(\mathrm{III})-\mathrm{Cr}(\mathrm{VI})$ by using functionalized Amberlite XAD-16 resin with dithioethylenediamine," Asian J. Chem., vol. 22, no. 8,2010 .

[38] I. Dolak, I. Tegin, R. Guzel, and R. Ziyadanogullari, "Synthesis and preconcentration of Amberlite XAD-4 resin modified by dithioethylenediamine," Asian J. Chem., vol. 21, no. $1,2009$.

[39] A. Islam, M. A. Laskar, and A. Ahmad, "Preconcentration of metal ions through chelation on a synthesized resin containing $\mathrm{O}, \mathrm{O}$ donor atoms for quantitative analysis of environmental and biological samples," vol. 185, pp. 2691-2704, 2013. [40] S. Saraçoğlu, “Chromosorb-102 Reçinesi Kullanılarak Katı Faz Özütleme Yöntemiyle Eser Elementlerin Zenginleştirilmesi ve AAS ile Tayini," Erciyes Üniversitesi Fen Bilimleri Enstitüsü, 2001. [41] V. Okumuş, S. Özdemir, E. Kılınç, A. Dündar, U. Yüksel, and Z. Baysal, "Preconcentration with Bacillus subtilis -Immobilized Amberlite XAD-16: Determination of $\mathrm{Cu} 2+$ and $\mathrm{Ni} 2+$ in River, Soil, and Vegetable Samples," Bioremediat. J., vol. 19, no. 1, pp. 47-55, 2015.

[42] G. O. El-Sayed, H. a. Dessouki, and S. S. Ibrahiem, "Removal of $\mathrm{Zn}(\mathrm{II}), \mathrm{Cd}(\mathrm{II})$ and $\mathrm{Mn}(\mathrm{II})$ From Aqueous Solutions By Adsorption on Maize Stalks," Malaysian J. Anal. Sci., vol. 15, no. 1, pp. 8-21, 2011.

[43] R. Onat, “Anoxybacillus sp.SO_B1 Bakterisi İle Modifiye Edilmiş Amberlit XAD-16 Reçinesi Kullanilarak ve $\mathrm{Pb}(\mathrm{II})$ 'nin Biyosorpsiyonu, Önderiştirilmesi ve AAS ile Tayini," Dicle Üniversitesi, Türkiye, 2011.

[44] A. Valdés García, M. Ramos Santonja, A. B. Sanahuja, and M. Del Carmen Garrigós Selva, "Characterization and degradation characteristics of poly( $\varepsilon$-caprolactone)-based composites reinforced with almond skin residues," Polym. Degrad. Stab., vol. 108, pp. 269-279, 2014.

[45] M. Soylak and Erciyes Üniversitesi, "Off-Line ve On-Line Katı Faz Özütleme Zenginleştirme Yöntemleri," 2007.

[46] H. Bağ, "Sepiolit kullanılarak bazı eser elementlerin zenginleştirme şartlarının araştırılması ve alevli atomik absorpsiyon spektroskopisi ile tayinleri," Gazi Üniversitesi Fen Bilimleri Enstitüsü, 1195.

[47] M. Soylak and M. Tuzen, "Coprecipitation of gold(III), palladium(II) and lead(II) for their flame atomic absorption spectrometric determinations," J. Hazard. Mater., vol. 152, no. 2, pp. 656-661, 2008. [48] K. O. Saygi, M. Tuzen, M. Soylak, and L. Elci, "Chromium speciation by solid phase extraction on Dowex M 4195 chelating resin and determination by atomic absorption spectrometry," J. Hazard. Mater., vol. 153, no. 3, pp. 1009-1014, 2008. 